\section{Stomatal Movement and Epidermal Water-Content}

Prof. D. Thoday has suggested ${ }^{1}$ that the remarkable stomatal behaviour of coffee may be explicable on a hypothesis involving variations in the water content of the epidermis as distinct from that of the leaf as a whole. As he says, a critical experiment would be the determination, in saturated air, of the relation between stomatal aperture and radiation. This has not been done.

However, the climatic range over which coffee is grown is wide : and I have determined its stomatal behaviour in semi-arid, cloudless, windy, unshaded and exposed conditions, and in moist, cloudy, shaded and almost wind free habitats. In the former, the relative humidity is very low, and the evaporating power of the air is consequently high. In the latter, the reverse is true, and relative humidity may remain very high throughout the day. Yet the relation between stomatal behaviour and incident radiation is similar in both habitats, and the stomata always close in strong light.

A sunfleck, illuminating one leaf on a coffee tree under dense shade and in a nearly saturated atmosphere, will cause rapid stomatal closure in that leaf, although physical evaporation and hence cuticular transpiration must be minimal.

It seems, therefore, unlikely that the peculiar stomatal behaviour of coffee, under these varied conditions, can be explained on the lines suggested.

East African Agricultural Research Station, F. J. NuTMan. Amani, Tanganyika Territory.

1 NATURE, 141, 164 (1938).

IN view of the information given by Mr. Nutman, I agree that my suggestion can scarcely apply. Mr. Nutman's observations appear to add a new type of response to the possible complexities of stomatal behaviour and make it still more evident that specific differences have to be considered.

D. THODAY.

\section{Penetration of Ultra-Violet Rays through Chitin}

Altenburg in 1928 found that the fluorescence of certain salts was only very slightly, if at all, affected when Drosophila melanogaster were interposed between the discharge tube of a Cooper Hewitt lamp and the salts at which the rays were directed. From this he concluded that the ultra-violet rays penetrated the chitin rather freely. His conclusion has been accepted by subsequent workers. Altenburg did not state, however, which salts were used, how many layers of flies there were, or how closely they were arranged. Besides, the shortest wave-lengths of visible light also cause fluorescence of salts.

In order to obtain more definite data, we planned experiments, using a Hanovia quartz mercury vapour lamp, to determine the limit of thickness of chitin that can still be penetrated effectively by the ultra-violet rays produced by this lamp. It was found that 60 minutes irradiation through a vitreosil plate $0.5 \mathrm{~cm}$. in thickness had a striking effect on the wing development of rather aged pupæ. The distance was maintained at 11 inches. Of the imagines which emerged, approximately 60 per cent showed distinct wing modifications of great variety. Undoubtedly the hypodermal cells between the two chitinous layers of the immature wings were effected by these rays which must, therefore, have penetrated effectively through the chitin of the puparium and of the pupal wing. The control flies were treated in the same manner but the dishes, instead of being covered by a vitreosil plate, were covered by ordinary glass of the same thickness.

The control material showed no effect even after several hours of irradiation, while a dosage of more than 80 minutes proved very deleterious to the experimental material. A uniform dosage of 60 minutes irradiation was maintained for all pupæ treated in these experiments. Besides the wing abnormalities observed, the viability of the experimental material, that is, the pupæ covered by vitreosil plate, was reduced by about 30 per cent as compared with the controls

This positive effect of the ultra-violet rays on the wing development suggested a means of testing out the effective penetrability of chitin to ultra-violet rays. For this purpose the flying wings of the locust Nomadacris septemfasciata were used in preparing small screens 2 in. $\times 2$ in. Sections of wings of this locust species showed that the thickness of the wing ranges from $4 \mu$ to $10 \mu$. The wings were carefully pasted on to frames of fairly thick paper, care having been taken to keep the window portion clean of paste. In this manner screens of 1-, 2-, 3- and 4-wing thickness respectively were made, and irradiation experiments carried out as stated above.

A spectrographic analysis was then made of the wave-lengths which penetrated the prepared chitin screens distinctly. The results are shown in the following table:

\begin{tabular}{|c|c|c|c|c|c|}
\hline \multicolumn{4}{|c|}{ Screen } & $\begin{array}{l}\text { Absorption } \\
\text { in A. }\end{array}$ & $\begin{array}{l}\text { Percentage wing } \\
\text { abnormalities }\end{array}$ \\
\hline $\begin{array}{l}0.5 \mathrm{~cm} \text {. } \\
4 \text { wings } \\
3 \text { wings } \\
2 \text { wings } \\
1 \text { wing } \\
\text { vitreosil } \\
\text { quartz le }\end{array}$ & $\begin{array}{c}\text { window } \\
\text { vitreosil } \\
\text { ", } \\
", \\
\ldots \\
\text { ens }\end{array}$ & $\begin{array}{l}\text { glass } \\
\ldots \\
\ldots \\
\ldots \\
\ldots \\
\ldots\end{array}$ & $\begin{array}{l}\cdots \\
\cdots \\
\cdots \\
\cdots \\
\cdots \\
\cdots\end{array}$ & $\left.\begin{array}{l}\varangle 3650 \\
<3650 \\
<3650 \\
<3125 \\
<2967 \\
<2534 \\
<2398 \\
<2225\end{array}\right\}(7)$ & $\begin{array}{r}0 \\
0 \\
0 \\
40 \\
54 \\
60 \\
62\end{array}$ \\
\hline
\end{tabular}

The spectrum was mapped from 1900 A. to $4400 \mathrm{~A}$. No lines were found below $2224 \cdot 7 \mathrm{~A}$. The range of the instrument is just outside the very intense mercury line $1849 \cdot 6 \mathrm{~A}$. As the absorption increases both with the increased thickness of the filters and with the decrease in wave-length, it is reasonable to suppose that light of wave-length $1849 \cdot 6 \mathrm{~A}$. will behave similarly to longer wave-lengths.

As a photo-densitometer was not available, quantitative expressions of absorption were not possible. It is hoped to rectify this in future experiments.

From these results it appears that our dosage was ineffective when the chitin layer was 3 wings (about $21 \mu$ ) thick or thicker ; the wave-length $3125 \mathrm{~A}$. was still biologically effective, but $3650 \mathrm{~A}$. and longer wave-lengths were not.

We wish to thank Prof. G. H. Stanley, director of the Minerals Research Laboratory for the use of apparatus and Mr. L. W. Vermeulen for technical assistance.

\section{Department of Zoology, and}

\section{G. ElofF.}

Minerals Research Laboratory, University of the Witwatersrand, Johannesburg.

Feb. 22.
V. L. Bosazza. 